\title{
Cell-cell contacts trigger programmed necrosis and induce cyclooxygenase-2 expression
}

\author{
J Bizik ${ }^{1,2}$, E Kankuri ${ }^{3}$, A Ristimäki ${ }^{1,4}$, A Taïeb ${ }^{5}$, H Vapaatalo ${ }^{3}$, \\ W Lubitz $^{6}$ and $A$ Vaheri, ${ }^{*}, 1,4$ \\ 1 Haartman Institute, University of Helsinki, POB 21, FIN-00014 Helsinki, Finland \\ 2 Cancer Research Institute, Laboratory of Tumour Cell Biology, SK-83391 \\ Bratislava, Slovakia \\ 3 Institute of Biomedicine, Pharmacology, University of Helsinki, POB 63, FIN- \\ 00014 Helsinki, Finland \\ ${ }^{4}$ Helsinki University Central Hospital, University of Helsinki, POB 21, FIN-00014 \\ Helsinki, Finland \\ ${ }^{5}$ Inserm EMI-U 02-17, Dermatology Unit, University of Victor Segalén, F-33076 \\ Bordeaux, France \\ ${ }^{6}$ Institute of Microbiology and Genetics, University of Vienna, A-1030 Vienna, \\ Austria \\ * Corresponding author: A Vaheri, Haartman Institute, University of Helsinki, PO \\ Box 21, FIN-00014 Helsinki, Finland. Tel: + 35891912 6490; \\ Fax: + 35891912 6491; E-mail: antti.vaheri@ helsinki.fi
}

Received 31.1.03; revised 17.7.03; accepted 28.7.03; published online 10.10 .03 Edited by D Nicholson

\begin{abstract}
Necrosis was induced by cell-cell contacts of human dermal fibroblasts in three-dimensional culture. Dramatic induction of cyclooxygenase-2 (COX-2) expression was found throughout these necrotizing cell clusters, whereas no increase in expression of apoptosis markers was seen. The cells were rapidly committed to necrosis, and the process could not be reversed by allowing them to spread and adhere on a solid substrate. Induction of COX-2 expression was accompanied by greatly enhanced production of the prostaglandins $E_{2}, I_{2}$, and $F_{2 x}$. When applied exogenously on necrotizing clusters, these prostaglandins delayed cell clustering and further enhanced COX-2 expression. Abolishing prostaglandin production by NS-398 or indomethacin reduced cell membrane damage (as measured by lactate dehydrogenase release into the culture medium). We also identified $\alpha$ enolase-mediated plasminogen activation as the major extracellular proteolytic executor of necrotic cell death. In contrast to inhibition of COX-2, inhibition of plasminogen activation failed to inhibit membrane damage associated with necrosis. Intracellular proteolysis, by caspases, was shown to take part in COX-2 induction. Taken together, our results indicate that cell-cell contacts induce an actively programmed necrotic process that functionally involves COX-2, a known hallmark of inflammation and cancer.
\end{abstract}

Cell Death and Differentiation (2004) 11, 183-195. doi:10.1038/

sj.cdd. 4401317

Published online 10 October 2003

Keywords: cyclooxygenase-2; human dermal fibroblasts; necrosis; plasminogen activation; prostaglandins

\begin{abstract}
Abbreviations: COX, cyclooxygenase; LDH, lactate dehydrogenase; NSAID, nonsteroidal anti-inflammatory drug; MTT, 3(4,5-dimethyl-thiazol-2-yl)-2,5-diphenyl-tetrazolium bromide; PG, prostaglandin; polyHEMA, poly(2-hydroxyethylmethacrylate); TUNEL, terminal deoxynucleotidyl-transferase-mediated dUTP nick-end labelling
\end{abstract}

\section{Introduction}

Cell death is an essential process in the generation of multicellular organisms, ${ }^{1}$ involving two pathways with distinct morphological characteristics: apoptosis and necrosis. ${ }^{2,3}$ Apoptosis, extensively investigated as programmed transcriptional activation of specific genes, ${ }^{4}$ has hallmarks which include the activation of endonucleases, consequent DNA degradation into oligonucleosomal fragments, and activation of caspases. ${ }^{5,6}$ The cytoplasm shrinks, but the organelles and plasma membrane retain their integrity for quite a long period. In vitro, apoptotic cells are ultimately fragmented into multiple membrane-enclosed spherical vesicles. In vivo, these apoptotic bodies are scavenged by phagocytes, inflammation is prevented, and cells die in 'immunological anonymity'. ${ }^{7}$

Necrosis has been referred to as accidental cell death caused by physical or chemical damage ${ }^{3,7}$ and has generally been considered an unprogrammed process. It is characterized by a pyknotic nucleus, cytoplasmic swelling, and progressive disintegration of cytoplasmic membranes, all of which lead to cellular fragmentation and release of material into the extracellular compartment. In necrosis, decomposition is principally mediated by proteolytic activity, but the precise identities of proteases and their substrates are poorly known. ${ }^{8}$ An elevation in cell-surface plasminogen binding and activation in damaged and dead cells has, however, been evident. $^{9}$

Within the foci of necrotizing cells, an acute inflammatory reaction ensues. ${ }^{10}$ Cell damage leads to failure to exclude calcium from the cell interior, resulting in the activation of calcium-dependent phospholipases. ${ }^{11}$ Arachidonic acid, liberated from membrane phospholipids by phospholipase $A_{2}$, serves as the precursor for consequent biosynthesis of eicosanoids, which play important roles in various cellular phenomena including inflammation, proliferation, differentiation, immune functions, and carcinogenesis. ${ }^{12,13}$ Cyclooxygenases (COXs) are rate-limiting enzymes in the conversion of arachidonic acid to prostanoids. COXs generate precursor prostaglandin (PG) endoperoxides, mainly $\mathrm{PGH}_{2}$, which are subsequently metabolized by specific isomerases to five primary bioactive prostanoids $\left(\mathrm{PGE}_{2}, \mathrm{PGD}_{2}, \mathrm{PGF}_{2 \alpha}, \mathrm{PGI}_{2}\right.$, and thomboxane $A_{2}, T_{x A}$ ). ${ }^{14}$ The constitutive COX isoform, COX-1, is expressed in most mammalian cells, whereas in most healthy tissues expression of the inducible isoform, COX-2, is ordinarily low or undetectable. ${ }^{14}$ COX-2 is encoded by an early-response gene ${ }^{15}$ and can be rapidly and strongly induced by serum, growth factors, proinflammatory cytokines, 
hormones, tumour promoters, or bacterial endotoxins. ${ }^{16}$ These findings suggest that COX-2 is responsible for synthesis of PGs at sites of inflammation, and these amplify pain and exacerbate fever and proinflammatory manifestations. ${ }^{13}$

Cell death in cultured cells can be induced by a variety of stimuli including physiological activators, physical trauma, microbes, environmental toxins, or chemical compounds. $^{3,7,17}$ Outcome usually depends on cell type and severity of stimulus. ${ }^{18}$ Effective inducers of necrosis in vitro include certain toxic compounds and heat shock. ${ }^{19}$ The type of cell death in the centre of spheroids established from tumour cells has been designated 'necrosis', with its development being considered a multifactorial event in which hypoxia is the main effector. ${ }^{20}$

Three-dimensional culture systems such as multicell spheroids mimic certain control mechanisms operating in vivo under various pathophysiological conditions. ${ }^{21}$ Spheroids have been particularly useful in studies focused on mimicking tumour nodules. ${ }^{21}$ Nodular growth is common in malignant, fast-growing tumours but can also appear in the skin as a result of the hyperproliferation of dermal fibroblasts characterized by distinctly greater cell density, as in dermal fibrosarcomas. $^{22}$ Most human cancer cell lines derived from solid tumours form growing spheroids. ${ }^{23}$ In contrast to tumour cells, normal adherent cells cannot be stimulated to grow as multicellular aggregates. ${ }^{23}$ It is evident that the growth of normal and tumour cells in three-dimensional arrangements is differently controlled.

Our aim was to characterize molecular mechanisms accompanying the death of normal cells in three-dimensional clusters. The rationale for choosing fibroblasts was that they are active participants in translating specific physiological signals ${ }^{16}$ and are the key sentinel cells to first recruit specific cells to sites of inflammation. ${ }^{24}$ We observed that clustering of these cells within spheroids is apparently a sufficient stimulus to trigger a series of spatio-temporal events leading to initiation and programmed progression of the process that culminates in upregulation of COX-2 and plasminogen activation, both evidently distinct consequences of necrotic cell death. It is important to note that this necrosis in fibroblast spheroids did not result from any extrinsic toxic compounds but was instead triggered by homotypic cell-cell interactions.

\section{Results}

\section{Clustering of dermal fibroblasts}

Prevention of fibroblast spreading on surfaces not favourable for attachment led to enhancement of homotypic cell-cell interactions, resulting in formation of multicellular clusters (Figure 1a). In our study, cluster formation was initiated in Ubottom 96-well plates treated with agarose, which formed a thin nonadherent film. Agarose represents one of the most efficient substrates to prevent cell attachment, ${ }^{23}$ but poly(2hydroxyethylmethacrylate) (polyHEMA), a nonionic compound which also prevents matrix deposition and subsequent cell attachment, worked equally well (data not shown). After the seeding of fibroblasts into the wells, they started to cluster, and the first loose aggregates were already seen after $2 \mathrm{~h}$ of incubation. Compact spheroids formed within $12 \mathrm{~h}$, reaching their final tight form by $24 \mathrm{~h}$ (Figure 1a). Once these aggregates were formed, the fibroblasts were so firmly attached to each other that the spheroids resisted disintegration by enzymatic treatment without showing substantial cell damage. The spheroids did not change in morphology during the next $24 \mathrm{~h}$ but then started gradually to decompose. This was visible as shedding of solitary shrunken and damaged cells and cellular fragments. The spheroid volume decreased as the degradation process continued, and after $120 \mathrm{~h}$ of incubation they were decomposed leaving remnants of dead cells, cellular fragments, and debris.

To assess cellular viability and metabolic activity of fibroblasts within the clusters, we applied MTT to the spheroid cultures and simultaneously to cultures of identical cell aliquots cultured as monolayers (Figure 1b). Two-dimensional cultures of fibroblasts grown on standard adherent plastic surfaces exhibited characteristic exponential growth, whereas the cells in spheroids showed quantitatively a different growth pattern: their metabolic activity was practically at a residual level when compared to that of monolayers, and gradually declined. In spheroids, however, some increase in metabolic activity was evident at $36 \mathrm{~h}$.

Conditioned media from these two types of cultures were also used for estimation of lactate dehydrogenase (LDH) release, which is considered a criterion for loss of membrane integrity. ${ }^{25}$ Concentration of $\mathrm{LDH}$ in the cultures with spheroids began to increase after $48 \mathrm{~h}$ of incubation, reaching a submaximal level at $84 \mathrm{~h}$ (Figure 1c). The amounts of LDH released from monolayer cultures were at a marginal level, but with prolonged incubation, after $72 \mathrm{~h}$ some increase occurred.

\section{Ultrastructure of decomposing spheroids}

Transmission electron microscopy demonstrated morphological changes in cells within the spheroids (Figure 2). Nuclei retained their typical morphology for up to $36 \mathrm{~h}$, but thereafter, some aggregation of chromatin into ill-defined masses was evident. This pattern was most distinct at $60 \mathrm{~h}$, but the integrity of nuclear membranes was still maintained. Later, the nuclei become pyknotic, and terminal spheroids showed mostly nuclear remnants. Marginal clumping of loosely textured nuclear chromatin was linked to early abnormalities, compatible with progression of necrosis. ${ }^{26}$ In spheroids after $48 \mathrm{~h}$ of incubation, phagolysosome-like dense bodies were numerous but patchy in their distribution; later they grew in size. Evidently, the spheroids underwent their most dramatic change in subcellular morphology after $48 \mathrm{~h}$, since at $60 \mathrm{~h}$ balloon-like and autophagic vacuoles were present throughout, and as the spheroid degradation proceeded these were the dominant structures within the cell bodies. Ultrastructural features appearing during the spheroid decomposition process were characteristic of necrosis.

\section{Expression of apoptosis-related genes in spheroids}

Fragmentation of chromatin is one of the hallmarks of apoptotic cell death. ${ }^{5}$ Our analysis of the genome integrity of 

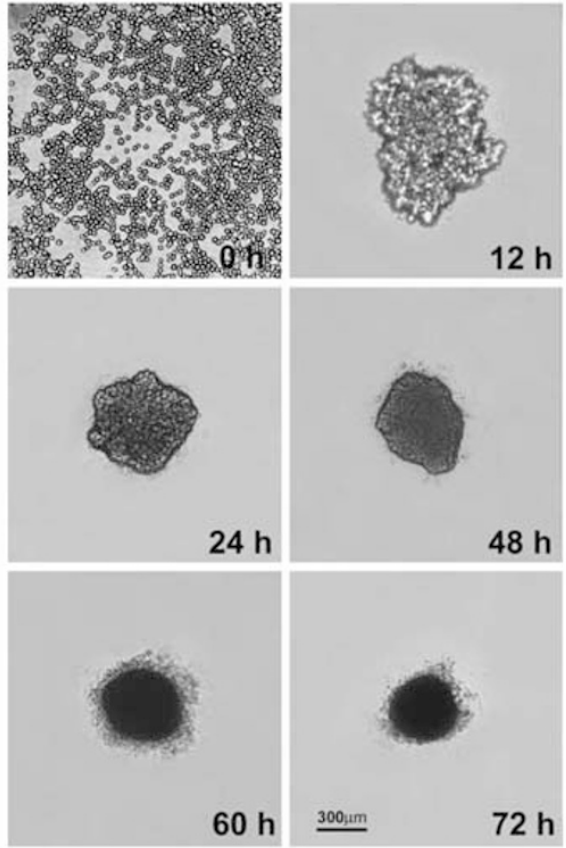

b

C
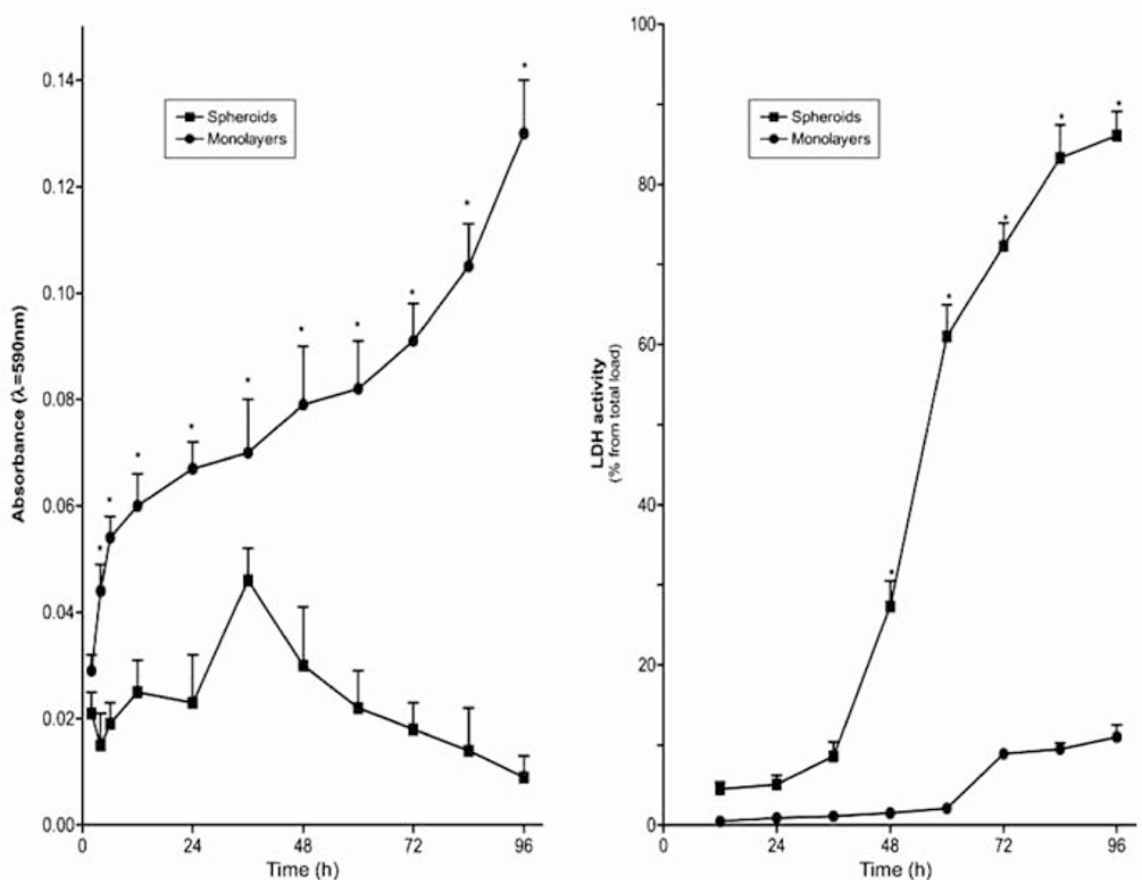

Figure 1 Morphology, metabolic activity, and LDH release during the formation and decomposition of dermal fibroblast spheroids. Aliquots of $1 \times 10^{4}$ cells were seeded to U-bottom wells treated with agarose to prevent cell spreading and cultured as described under 'Material and Methods'. (a) Phase-contrast microphotographs of the spheroids taken at the indicated time points $(\mathrm{bar}=300 \mu \mathrm{m}$ ). Cellular debris around spheroids is indicative of decomposition after $48 \mathrm{~h}$ of incubation. (b) Cells were grown concurrently as three-dimensional spheroids (- -) or monolayers (- -). Metabolic activity measured by MTT assay. Substrate MTT was added to cultures at different time points and incubated for $30 \mathrm{~min}$. Substrate conversion to formazan was estimated by its optical density at $590 \mathrm{~nm}$. (c) Membrane leakage was measured by LDH activity in conditioned medium harvested at indicated time points after addition of specific substrate. Optical density was measured and values expressed as percentage of total initial load. Data are means of triplicate cultures + S.E.M. ${ }^{*} P<0.001$ between cultures

DNA isolated from the spheroids by agarose gel electrophoresis revealed no fragments suggestive of interchromosomal DNA cleavage, even in highly decomposed spheroids, for example after $96 \mathrm{~h}$ of incubation (data not shown). We also performed terminal deoxynucleotidyltransferase-mediated dUTP nick-end labelling (TUNEL) staining of sectioned spheroids (Figure $3 \mathrm{a}$ ). In spheroids until $48 \mathrm{~h}$ of incubation less than $1 \%$ of cells were positive for DNA breaks, whereas 


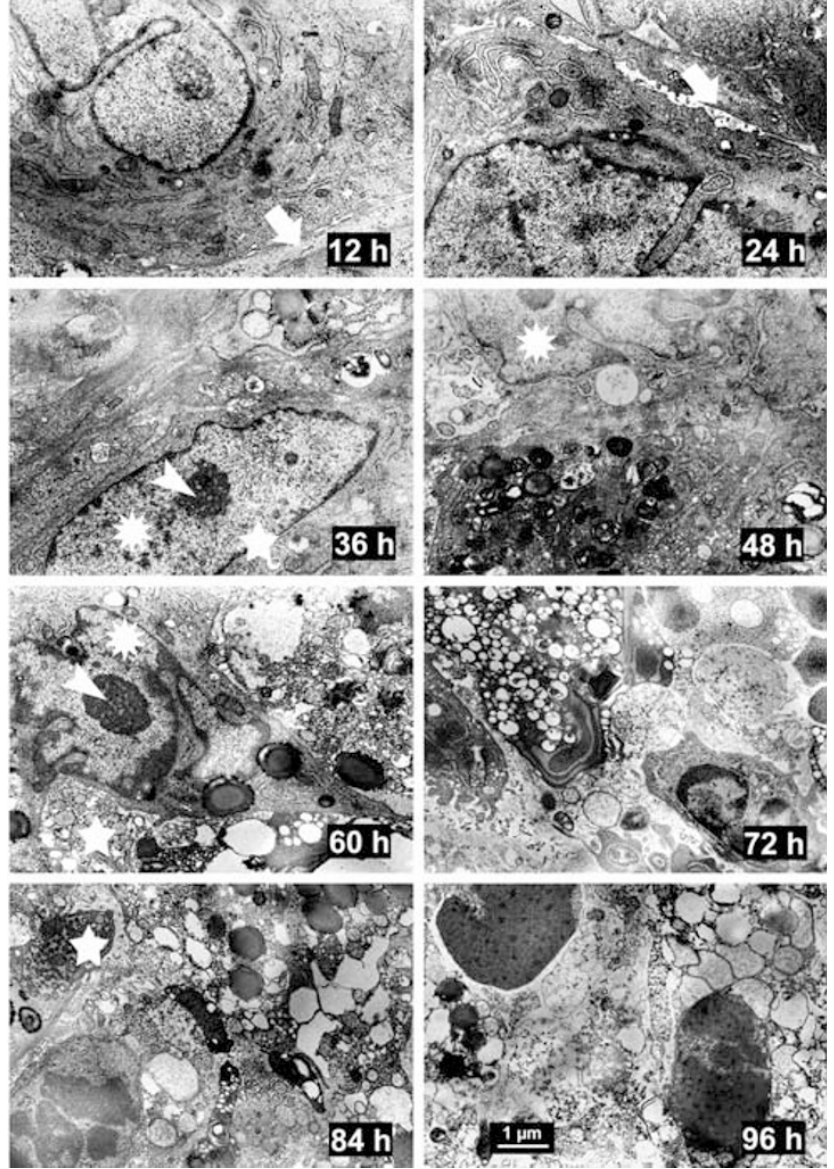

Figure 2 Transmission electron microscopical images of multicell spheroids. Samples of fibroblast spheroids collected at $12 \mathrm{~h}$ time intervals after seeding were processed for electron microscopy. Note the appearance of lysosomal dense bodies after $48 \mathrm{~h}$ as well as characteristic vacuole-rich cells. The characteristic features of necrosis are shown in the figure by symbols: $\Rightarrow$, after $24 \mathrm{~h}$ the cell boundaries become indistinct; gross swelling of the mitochondria; *, marginal clumping of loosely textured nuclear chromatin; - nucleolus is evident as a compact body while cytoplasmic degradation advances. Bar $=1 \mu \mathrm{m}$

after $96 \mathrm{~h}$ the majority were positive. As an indicator of necrosis, distinct TUNEL positivity occurred only during later stages of decomposition. $^{27}$

As most cells undergoing apoptosis are dependent on specific gene transcription and consequent de novo protein synthesis, ${ }^{4}$ we analysed the expression of some proteins involved in the apoptotic pathway: Bax, p53, the cell-surface receptor Fas, and the death-associated protein Daxx. ${ }^{28}$ All these proteins showed their highest expression in the early spheroids, but it declined as the spheroids decomposed. There was no evidence of upregulation of the antiapoptotic $\mathrm{Bcl}-2$ protein (Figure $3 \mathrm{~b}$ ). No active caspase-3, which plays a crucial role in the execution of the apoptotic process, ${ }^{6}$ was detected. Procaspase-3 expression had a similar pattern to that of the other components of apoptosis studied. The activity of caspase-3 was further evaluated with the aid of a specific substrate, Z-DEVD-AMC. No induction of caspase-3 activity was seen in the spheroids as compared to corresponding control monolayer cultures (data not shown). The apoptosisinducer camptothecin markedly induced caspase-3 activity (data not shown). a
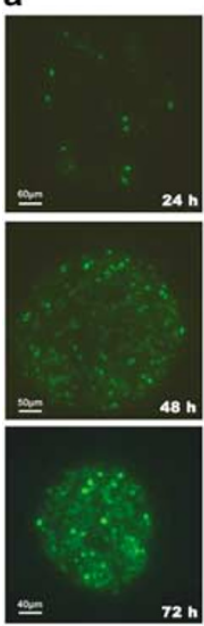

b
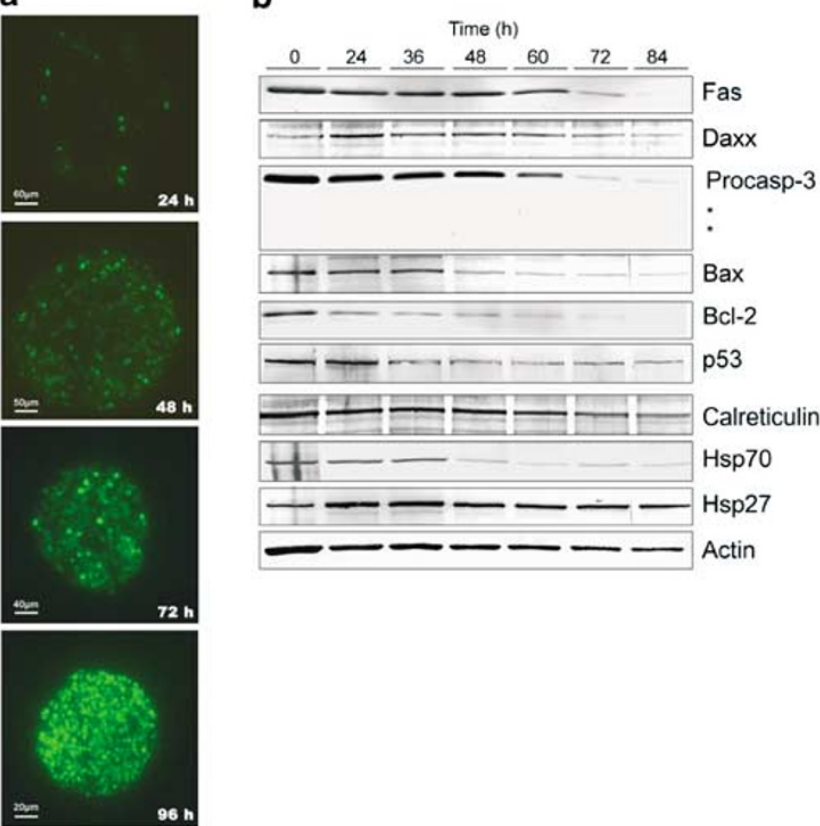

Figure 3 Presence of DNA breaks and expression of apoptosis-related genes in spheroids. (a) Fibroblasts were cultured as spheroids, and $5 \mu \mathrm{m}$ sections were processed for TUNEL staining (as marker of DNA breaks) by the in situ cell death detection kit. Positive cells were observed by microscopy and detected as fluorescein-positive granules. (b) Expression of selected apoptosis-related proteins was detected by immunoblotting with specific antibodies. Asterisks indicate presumed positions of active forms of caspase-3 as cleaved from procaspase-3 (Procasp-3) according to molecular weight markers. Samples represent identical numbers of spheroids collected at indicated time points. Expression of actin demonstrates the actual protein content per sample. Figures show representative results from three experiments

Heat shock proteins confer cellular protection against a variety of cytotoxic stress conditions and also against physiological stress associated with growth arrest or receptor-mediated apoptosis. ${ }^{28} \mathrm{Hsp} 27$ and Hsp70 in particular may directly affect the execution of apoptotic signalling pathways by their capability to increase survival of cells exposed to a variety of lethal stimuli. ${ }^{29}$ We therefore analysed expression of these two proteins as well as that of calreticulin, an endoplasmic reticulum-specific chaperone, which facilitates induction of apoptosis. ${ }^{30}$ A similar decline in band intensity occurred as for apoptosis-related genes (Figure $3 \mathrm{~b}$ ).

\section{Temporal expression patterns of COXs in spheroids}

Since it is well established that the process of necrosis often elicits an inflammatory response, we studied expression of COX enzymes during spheroid formation and subsequent decomposition (Figure 4a). In the clusters, COX-1 expression was only slightly increased, whereas COX-2 was dramatically elevated after $48 \mathrm{~h}$ of incubation, reached a peak at $60 \mathrm{~h}$, and then gradually declined. The highest value represented an up to 30-fold increase, as estimated by densitometric scanning (Figure 4b). In contrast, monolayer cultures showed little or no increase in COX-2 expression during the entire period of incubation. 
a

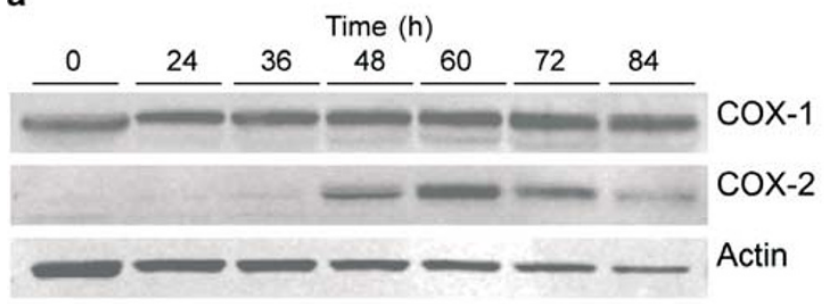

b

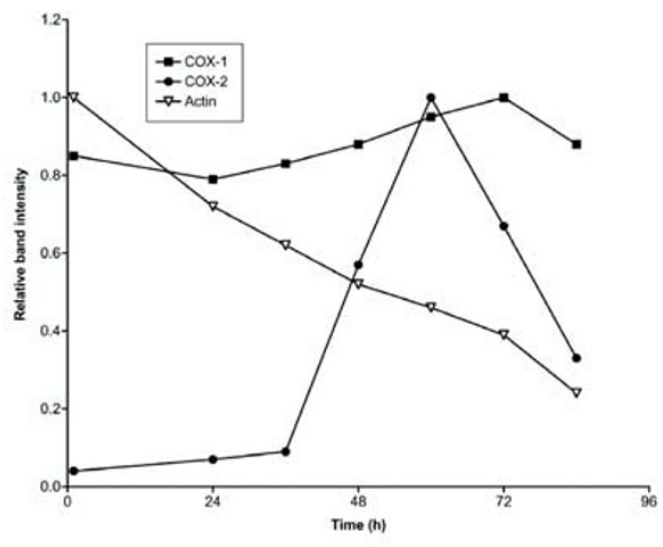

C

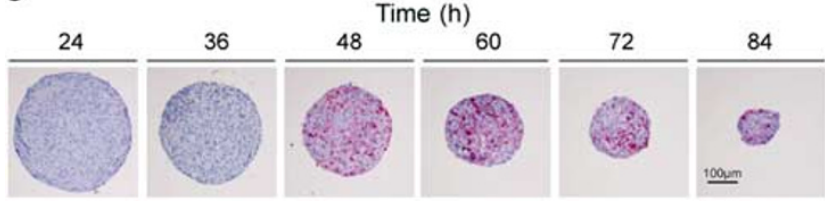

Figure 4 Time course of COX-1 and COX-2 expression in dermal fibroblast spheroids. (a) Cells were cultured as spheroids, collected at indicated time points, and the same number of spheroids processed for immunoblot analysis. The gradually decreased content of actin served as a representative intracellular control component and a marker of spheroid degradation. Experiments were conducted at least three times, and the figure shows immunoblots from a representative experiment. (b) The relative density of individual bands was quantified by densitometric scanning, and highest density in a series was considered 1.0. (c) Immunohistochemical detection of COX-2 protein expression within spheroids was performed on paraffin-embedded sections. Bar $=100 \mu \mathrm{m}$

\section{Homogenous expression of COX-2 in cells within spheroids}

A portion of the spheroid aliquots was harvested for electron microscopy, and was paraffin-embedded and processed for immunohistochemistry. After $36 \mathrm{~h}$ of incubation, expression of COX-2 in spheroids was intensively induced (Figure 4c) and evidently accompanied the decomposition process. It is interesting that all cells as a contiguous cellular mass within the spheroid were uniformly affected by the stimulus which caused COX-2 expression. Notably, no enrichment of COX-2 was evident in the centre of the spheroid, where nutrient deprivation and hypoxia were presumably the highest. This observation clearly indicates synchronous signalling, which triggered COX-2 upregulation across the whole spheroid.

\section{Reflection of COX activity in the prostanoid profile of cell culture supernatants}

As compared with prostanoid production of monolayer cultures at $36-84 \mathrm{~h}$, spheroid COX activity was considerably
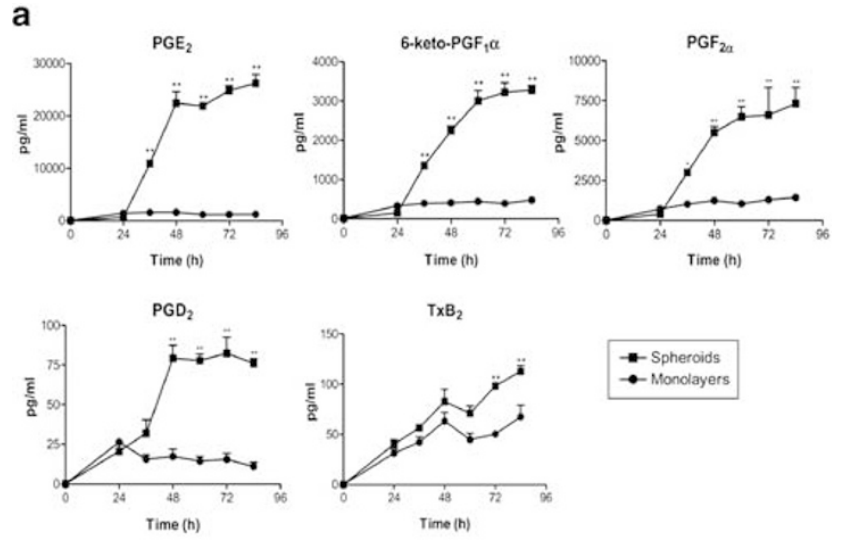

b
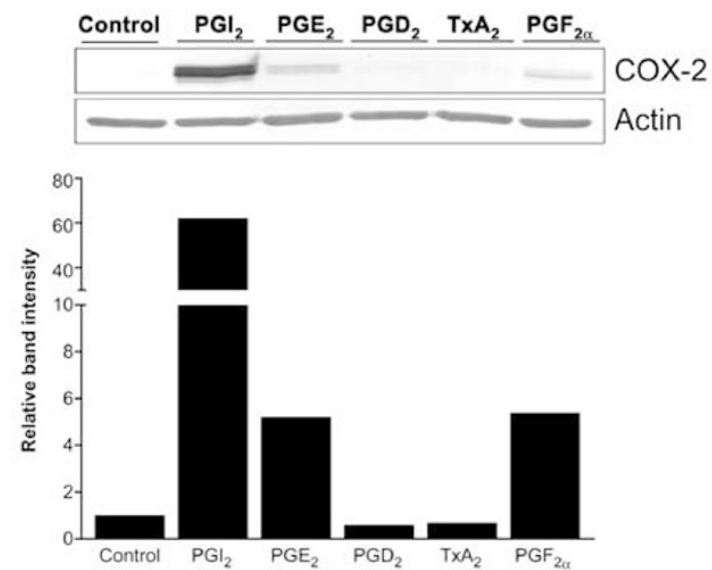

Figure 5 Production of prostanoids by dermal fibroblast spheroids, and effect on COX-2 expression. (a) Concentrations of the five primary prostanoids $\mathrm{PGE}_{2}$, $\mathrm{PGI}_{2}$ (measured as its stabile metabolite 6-keto-PGF ${ }_{1 \alpha}$ ), $\mathrm{PGF}_{2 \alpha}, \mathrm{PGD}_{2}$, and thromboxane $A_{2}\left(T x A_{2}\right.$, measured as its stabile metabolite $\left.T x B_{2}\right)$ were measured in the conditioned media of spheroids and corresponding control monolayers at indicated time points. Each sample was pooled from 15 wells, and the estimation was carried out in triplicate. Data are mean + S.E.M. ( $n=3$ in each). (b) To test the influence of prostanoids on the expression level of COX-2, formation of spheroids was initiated in the presence of exogenous prostanoids $(100 \mu \mathrm{g} / \mathrm{ml})$ as indicated in the figure. Cultures were incubated for $36 \mathrm{~h}$, and spheroids were processed for immunoblotting with specific antibodies. The relative density of individual bands was quantified by densitometric scanning; the vehicle control band was assigned as 1.0. The result is representative of three experiments

higher (Figure 5a). They produced large amounts of $\mathrm{PGE}_{2}$, $\mathrm{PGF}_{2 \alpha}$, and $\mathrm{PGI}_{2}$ (measured as 6-keto $\mathrm{PGF}_{1 \alpha}$ ). Production of $\mathrm{PGD}_{2}$ and $\mathrm{TXA}_{2}$ (measured as $\mathrm{TXB}_{2}$ ) was also greater in the spheroids, but the concentrations remained at relatively low levels. Production of $\mathrm{PGE}_{2}, \mathrm{PGF}_{2 \alpha}$, and $\mathrm{PGI}_{2}$ reflects $\mathrm{COX}-2$ activity, since their increases coincided quite precisely with induction of COX-2 protein levels. The persistence of COX-1 expression as compared to that of COX-2 in spheroids after $72 \mathrm{~h}$ may be reflected in their increased production of $\mathrm{TxA}_{2}$ (Figure 5a).

\section{Induction of COX-2 expression by exogenous prostanoids}

Spheroids incubated for 4 days without change of culture medium reproducibly expressed the maximal level of COX-2 at $60 \mathrm{~h}$ of culture. When the medium was changed every $24 \mathrm{~h}$, 
peak COX-2 expression was delayed by $18 \mathrm{~h}$ (data not shown), suggesting that metabolites produced by the cells influenced COX-2 expression. As PGs can exert positive regulatory feedback on the expression of COX enzymes, ${ }^{31}$ we tested the effect of $\mathrm{PGE}_{2}, \mathrm{PGD}_{2}, \mathrm{PGI}_{2}, \mathrm{PGF}_{2 \alpha}$, and $\mathrm{TxA}_{2}$ on induction of COX-2 in the spheroids. As shown in Figure $5 b$, $\mathrm{PGI}_{2}$ upregulated COX-2, whereas $\mathrm{PGE}_{2}$ and $\mathrm{PGF}_{2 \alpha}$ were only moderate inducers. The exogenously applied PGs accelerated the appearance of COX-2 expression only when they were added at the time of seeding of the spheroids. If they were applied later during spheroid formation, they failed to further enhance the COX-2 expression induced by clustering per se. These experiments suggest that homotypic cell-cell interaction acts as the major stimulus for COX-2 expression. Nevertheless, certain PGs produced in the process of necrosis promoted COX-2 upregulation.

\section{Effect of exogenous prostanoids on clustering and estimation of the point of no return}

In the same experimental setting as above, we investigated the influence of exogenous prostanoids on clustering in the early stages of spheroid formation. Figure 6a demonstrates their effect on the volume of cell clusters as followed by microscopy. Most notably $\mathrm{PGI}_{2}$, but also $\mathrm{PGE}_{2}$ and $\mathrm{PGF}_{2 \alpha}$ delayed aggregation for up to $9 \mathrm{~h}$. Later, no differences appeared between prostanoid- and vehicle-treated cells. These results suggest that intrinsic COX-2 activity may also be intended for an antiaggregatory purpose, since the production of these same PGs was upregulated during clustering.

In the process of cell death, the point of no return marks a set of irreversible changes triggering unavoidable death. ${ }^{3}$ Assuming that clustering of fibroblasts is principally the causative stimulus for necrosis, its elimination can rescue the cells from death. We adopted upregulation of COX-2 and degradation of actin as two variables related to the extent of necrosis. Escape from necrosis should be evidenced by proportional downregulation of COX-2 and simultaneous preservation of actin. Spheroids were preformed in U-well plates for the time periods indicated and then transferred to standard culture dishes, allowing them to adhere and spread. All cultures, including control spheroids not allowed to spread, were cultured simultaneously up to $60 \mathrm{~h}$ in order to reach maximal expression of COX-2, and then were harvested and processed for immunoblotting. It is evident from Figure $6 \mathrm{~b}$ that the cells that had clustered for $12 \mathrm{~h}$ expressed $90 \%$ of COX-2, and the actin in these cells was degraded to the same extent as detected in control spheroids. Densitometric estimation of both COX-2 and actin showed that clustering for $3 \mathrm{~h}$ is sufficient to commit $50 \%$ of the cell mass to necrosis.

\section{Effect of nonsteroidal anti-inflammatory drugs (NSAIDs) on COX-2 expression and LDH release}

In spheroids, the effects of indomethacin, a nonselective COX inhibitor, and of NS-398, a selective COX-2 inhibitor, on expression of COX-2 were evaluated at $60 \mathrm{~h}$ of culturing. The $60 \mathrm{~h}$ time point was selected in order to reveal exacerbation or

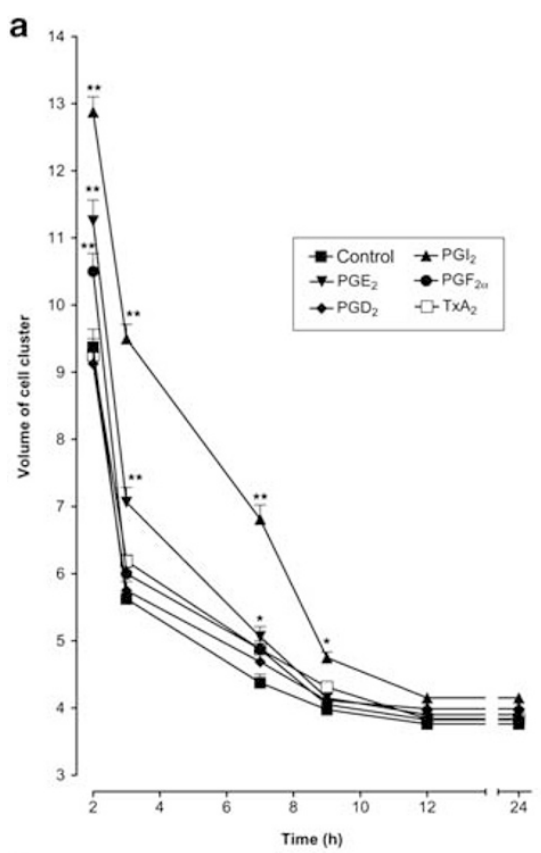

b
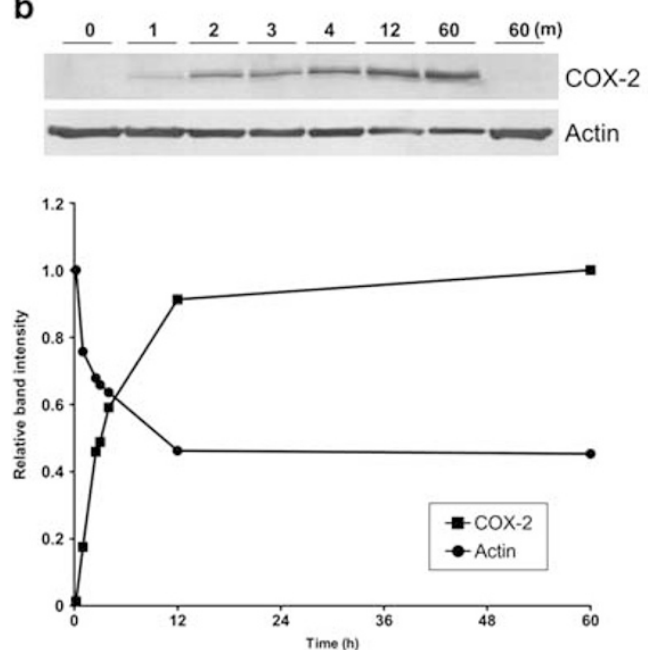

Figure 6 Effect of exogenous prostanoids on multicell cluster formation and characterization of the point of no return. (a) After seeding, dermal fibroblasts were treated with different prostanoids (final concentrations $100 \mu \mathrm{g} / \mathrm{ml}$ ) as indicated and followed for $24 \mathrm{~h}$. The chart shows the calculated volume of spheroids after treatment. Data are presented as mean + S.E.M. ( $n=8$ each). ${ }^{\star} P<0.05,{ }^{* \star} P<0.001$ as compared to vehicle-treated control. (b) Cell aliquots were cultured as spheroids for indicated time periods and then transferred to standard culture dishes to allow spreading and growth as monolayers. All cultures including those control spheroids not allowed to attach and spread were cultured for a total of $60 \mathrm{~h}$. Cell lysates were then processed for immunoblotting. Intensity of staining for COX-2 represents commitment towards necrosis; staining for actin shows the extent of decomposition. Sample $60(\mathrm{~m})$ is an additional control, the aliquot of a lysate from cells cultured for $60 \mathrm{~h}$ as a monolayer. Note lack of COX-2 expression and high amount of actin, reflecting actively proliferating cell culture. The relative density of individual bands was quantified by densitometric scanning, with the highest density in a series considered as 1.0. The figure represents three experiments

inhibition of the selected variables, induced COX-2 levels, and submaximal LDH release (see Figure 1c).

Both NSAIDs inhibited COX-2 expression at relatively high concentrations (50-250 $\mu \mathrm{M})$; this effect was, however, more 
pronounced with NS-398 (at approximately five-fold lower concentrations) than with indomethacin (Figure 7a). COX-2 activity was completely blocked by the NSAIDs at $1 \mu \mathrm{M}$ concentrations, as estimated by $\mathrm{PGE}_{2}$ levels (Figure $7 \mathrm{~b}$ ). At this concentration, both indomethacin and NS-398 significantly reduced $\mathrm{LDH}$ release from the spheroids: by 45 and $57 \%$, respectively (Figure $7 \mathrm{c}$ ). Since at $1 \mu \mathrm{M}$, both NSAIDs completely abolished $\mathrm{PGE}_{2}$ production but showed no effect on COX-2 expression, these results suggest that the
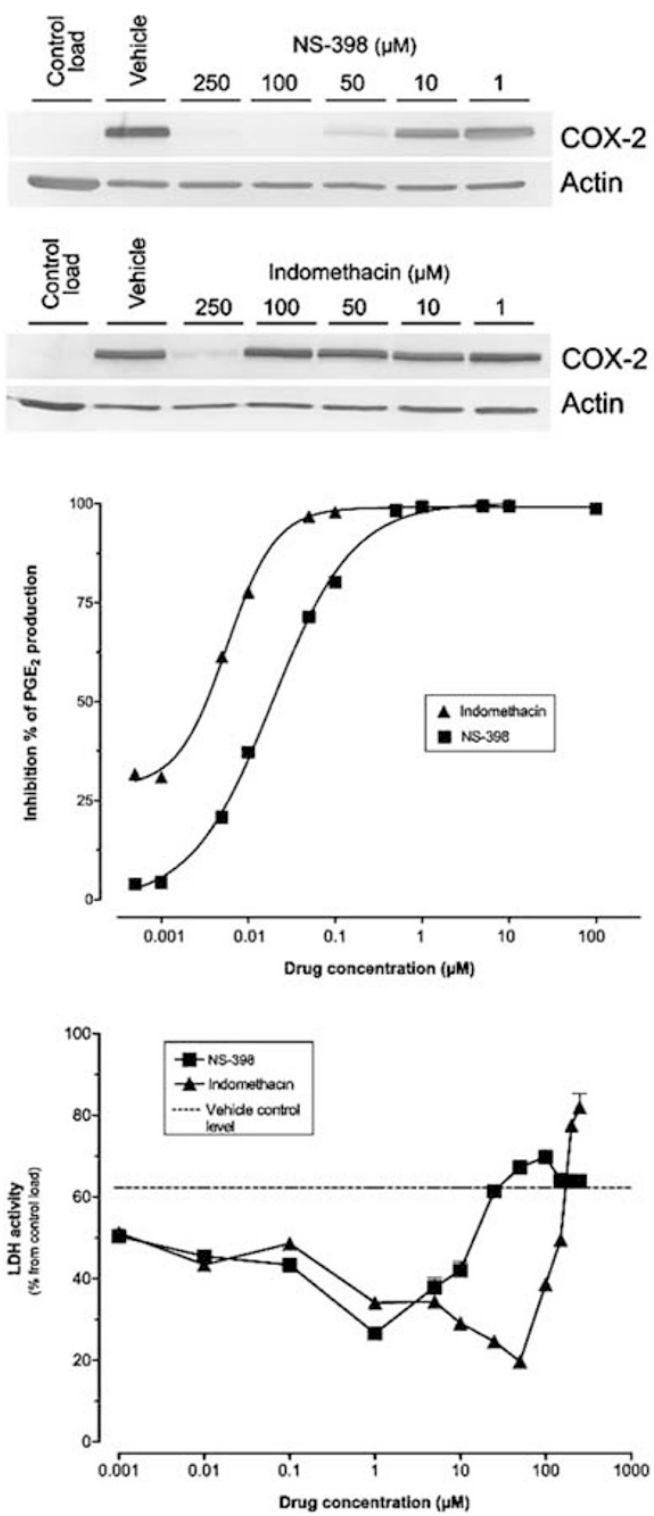

Figure 7 Effect of NSAIDs on COX-2 expression and LDH release. Concentrations of NS-398 or indomethacin were added to cultures of dermal fibroblasts at seeding, and spheroids were cultured for $60 \mathrm{~h}$. (a) Expression of COX-2 was detected by immunoblotting. (b) Concentrations of $\mathrm{PGE}_{2}$, as a measure of COX-2 activity, were analysed from conditioned media of fibroblast spheroids from the experiments. The figure shows inhibition of production of $\mathrm{PGE}_{2}$ in spheroids by indomethacin $\left(-\boldsymbol{\Lambda}_{-}, \mathrm{IC}_{50}=5.6 \mathrm{nM}\right)$ and NS-398 $(-\boldsymbol{-}-$, $\mathrm{IC}_{50}=19 \mathrm{nM}$ ) relative to vehicle-treated control values. (c) The activity of $\mathrm{LDH}$ in conditioned media was estimated as a measure of cell decomposition. Data are presented as mean + S.E.M. ( $n=3$ each) spheroids' intrinsic COX-2 activity is insufficient to exert an autocrine effect on COX-2 expression. When applied at higher concentrations, both NSAIDs inhibited COX-2 expression, perhaps reflecting these drugs' nonspecific or even toxic action (as evidenced by elevated LDH release, see Figure $7 \mathrm{c}$ ).

\section{Effect of caspase inhibition on COX-2 expression and cell membrane leakage}

Even though no expression of active caspase-3 nor increased caspase-3 activity was observed in the spheroids, we evaluated the role of the caspase family of enzymes by utilizing a cell-permeable, irreversible, and polycaspase inhibitor, Z-VAD-FMK. This inhibitor concentration-dependently reduced expression of COX-2 (Figure 8a), and inhibited membrane damage (Figure $8 b$ ) by up to $40 \%$. These results suggest that the necrotic cell death programme in human fibroblast spheroids is not caspase-independent, but may utilize these universal proteases in the activation of signalling molecules that drive the proinflammatory response as well as in the execution of the death decision.

\section{Effect of extracellular calcium on COX-2 expression and cell membrane leakage}

Calcium is important for homotypic cell-cell adhesion, that is, the formation of intercellular adherent junctions in human fibroblasts. It has also been implicated in disintegration of cells through the activity of $\mathrm{Ca}^{2+}$-sensitive protein-digesting

a
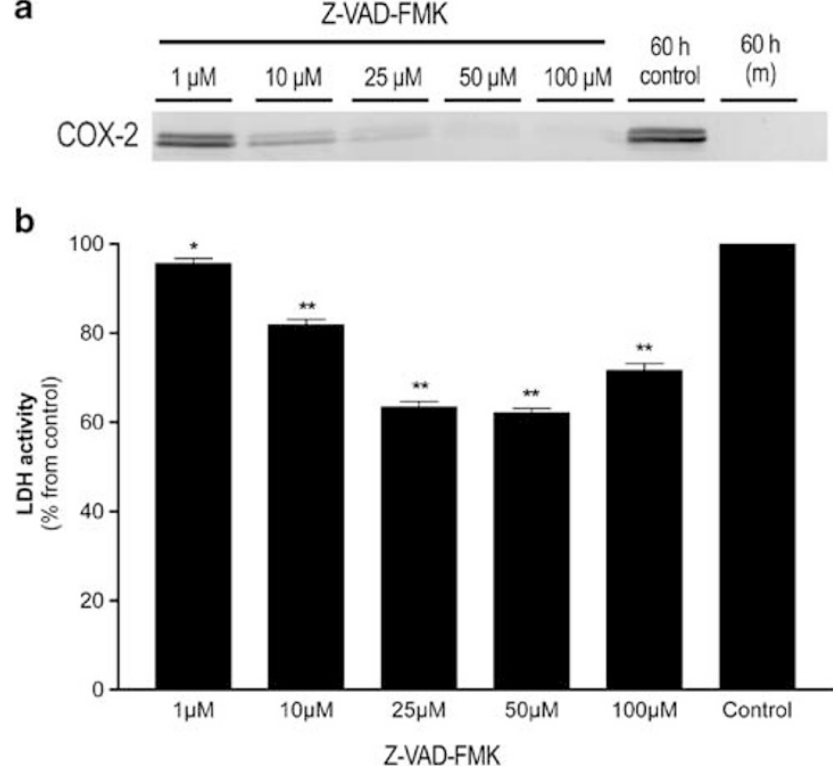

Figure 8 Effect of the polycaspase inhibitor Z-VAD-FMK on COX-2 expression and $\mathrm{LDH}$ release. The effect of caspase inhibition on induction of COX-2 and on membrane leakage was evaluated at $60 \mathrm{~h}$ of spheroid formation using an inhibitor of the caspase family of enzymes, Z-VAD-FMK. (a) Expression of COX-2 in fibroblast spheroids after treatment with different concentrations of Z-VAD-FMK. The expression levels of COX-2 in control spheroids ( $60 \mathrm{~h}$ control) and monolayers $(60 \mathrm{~h}(\mathrm{~m}))$ without the inhibitor are shown. (b) Effect of Z-VAD-FMK on $\mathrm{LDH}$ release in fibroblast spheroids at $60 \mathrm{~h}$ of incubation. ${ }^{\star} P<0.01$, ${ }^{\star \star} P<0.001$ as compared to control spheroid cultures without inhibitor 
a
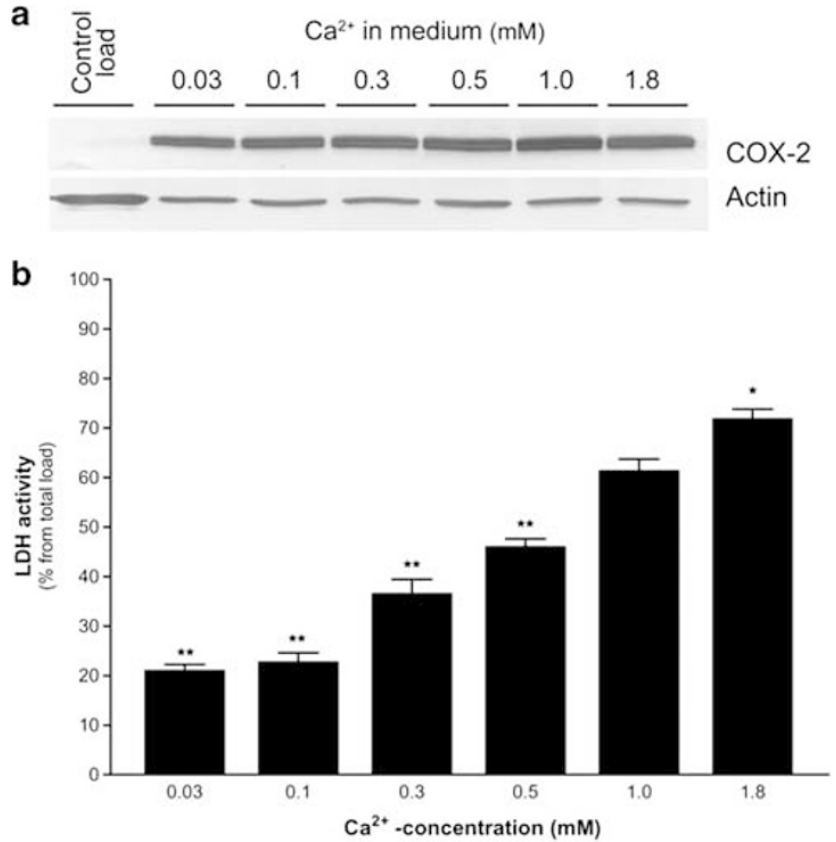

Figure 9 Influence of extracellular calcium concentrations on COX-2 expression and LDH release. Formation of dermal fibroblast spheroids was allowed to proceed for $60 \mathrm{~h}$ in culture medium containing indicated concentrations of calcium. (a) Expression of COX-2 was analysed by immunoblotting. (b) LDH activity was estimated in conditioned media as a measure of cell decomposition. Data are presented as mean + S.E.M. of three experiments. ${ }^{\star} P<0.01,{ }^{* \star} P<0.001$ as compared to culture media containing $1.0 \mathrm{mM}$ calcium

enzymes. ${ }^{32}$ To assess the effect of extracellular calcium on COX-2 expression and on decomposition of spheroids, the cells were cultured in a series of culture media containing gradually increasing calcium concentrations of $0.03-1.8 \mathrm{mM}$. No differences in cluster formation or in spheroid appearance were observable even in low calcium-level media (0.03 and $0.1 \mathrm{mM}$ ) (data not shown). Figure 9a, b shows that upregulation both of COX-2 expression and of $\mathrm{LDH}$ release was dependent on the extracellular calcium concentrations. Nevertheless, these results indicate the possibility that calcium is not essential for those types of cell-cell interactions that create signalling (as evidenced by persistent COX-2 induction despite low calcium levels) consequently committing the system to necrosis.

\section{Plasminogen activation in spheroids}

Figure 10a demonstrates that the extent of plasmin generated by spheroids was at least one order of magnitude higher than that by monolayers. Since plasmin is generated at the cell surface, it is important to note that the surface area of spreadout fibroblasts is up to 50 times as large as that of the spheroids. Immunoblotting of cell lysates revealed that as the decomposition of spheroids progressed, expressions of tissue-type plasminogen activator (tPA), of urokinase (UPA), and of UPA receptor (UPAR) gradually decreased (Figure $10 \mathrm{~b})$. In the early spheroids, the expression of plasminogen activator inhibitor-1 (PAl-1) was upregulated and thereafter remained quite steady. Expression of the nonglycosylated precursor of PAI-2 also remained steady. In contrast, as

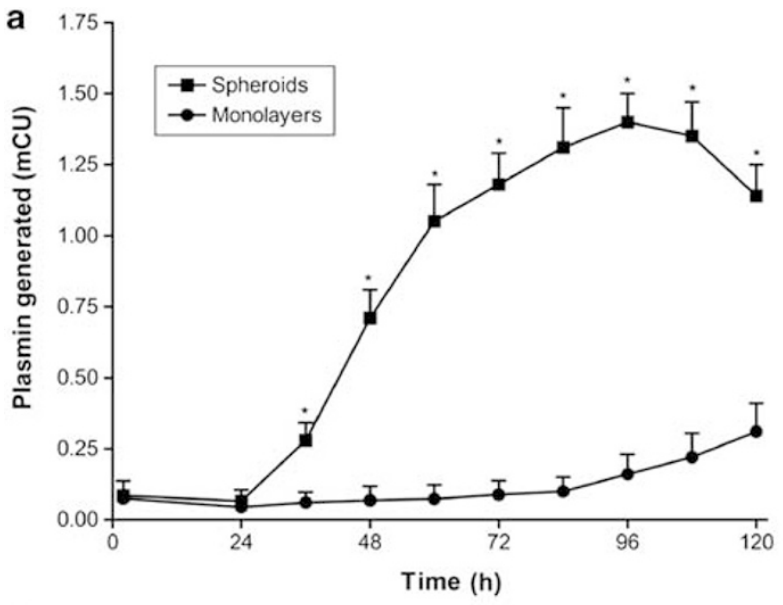

b
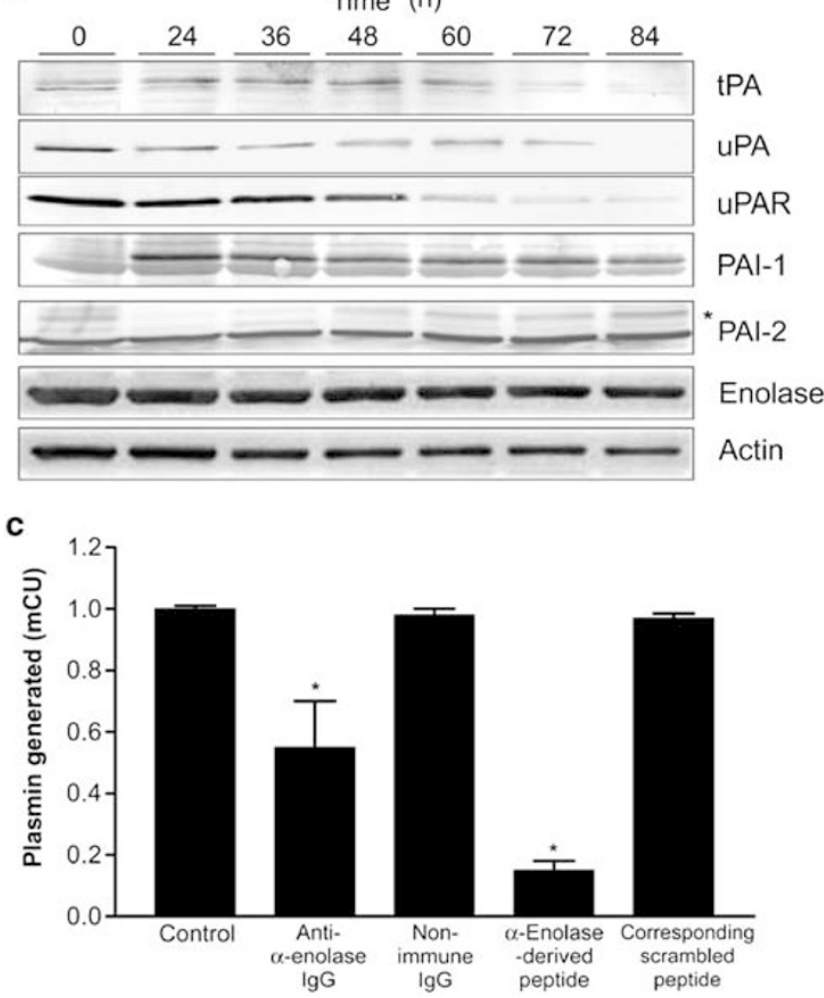

Figure 10 Plasminogen activation in fibroblast spheroids. (a) Cells in paralle were cultured as spheroids and standard monolayers. Human plasminogen $(50 \mu \mathrm{g} / \mathrm{ml})$ was added for $2 \mathrm{~h}$. Generated plasmin was recovered with $1 \mathrm{mM}$ tranexamic acid, with its activity estimated with a specific substrate. Data are presented as mean + S.E.M. ( $n=9$ for each). ${ }^{*} P<0.001$ as compared to control monolayers at indicated time points. (b) Expression of the main components of the plasminogen activation cascade in spheroids was detected by immunoblotting. Samples represent identical numbers of spheroids collected at indicated time points. Expression of actin served as a control to demonstrate the actual protein load. The figure shows representative immunoblots from three experiments. The asterisk marks the glycosylated form of PAI-2. (c) Influence of $\alpha$-enolase mimetic peptide and effect of anti- $\alpha$-enolase antibody were tested for plasminogen activation on decomposed spheroids. Fibroblasts were cultured for $60 \mathrm{~h}$ as spheroids. Then, parallel series of spheroids were incubated in the presence of human plasminogen $(50 \mu \mathrm{g} / \mathrm{ml})$ along with the anti- $\alpha$-enolasespecific $\operatorname{lgG}(5 \mu \mathrm{g} / \mathrm{ml})$, control nonimmune $\operatorname{lgG}(10 \mu \mathrm{g} / \mathrm{ml}$ each), specific peptide $(250 \mu \mathrm{M})$, and corresponding scrambled peptide $(500 \mu \mathrm{M})$ for $2 \mathrm{~h}$. The plasmin was recovered by $1 \mathrm{mM}$ tranexamic acid and quantified as above. ${ }^{*} P<0.001$ as compared to vehicle control 
necrosis progressed, expression of the glycosylated form of $\mathrm{PAI}-2$ began to appear. The increase in plasmin generation was apparently not a result of upregulation of any of the main regulatory components taking part in the plasminogen activation cascade, or alternatively a result of downregulation of either PAl-1 or PAl-2.

In addition to proteins with carboxy-terminal lysines that bind plasminogen, ${ }^{33}$ also certain intracellular proteins such as $\alpha$-enolase, when on cell surfaces, are able to bind plasminogen and promote its activation. The plasminogen-binding portion of $\alpha$-enolase has been mapped to a 16-amino-acidlong peptide $\left({ }^{257}\right.$ DLDFKSPDDPSRYISP $\left.{ }^{272}\right) .{ }^{34}$ When applied to spheroids, this mimetic peptide at $500 \mu \mathrm{M}$ concentration inhibited plasminogen activation by $79 \%$, whereas the corresponding scrambled peptide (amino-acid sequence SPDSYLPDRFDKSIDP) had no effect (Figure 10c). These results indicate that plasmin generation by decomposed spheroids is substantially mediated by $\alpha$-enolase. Antibodies directed against $\alpha$-enolase, at $5 \mu \mathrm{g} / \mathrm{ml}$, maximally inhibited plasminogen activation by only $32 \%$. Further increase in antibody concentration actually had the reverse effect on conversion of plasminogen, perhaps due to the fact that IgG molecules contain lysine at the carboxy end, which can serve as a binding site for plasminogen. ${ }^{35}$ No further inhibition could thus be gained by the use of antibodies.

\section{Discussion}

Morphological and experimental evidence has shown that cell death in multicellular organisms can principally be classified into two main categories: apoptosis and necrosis. ${ }^{2}$ An important fact is that apoptosis typically affects scattered cells in tissues, whereas necrosis usually occurs within tracts of contiguous cells. ${ }^{26}$ In general, necrosis has been considered to be processed in a passive manner by environmental perturbation rather than by any active intrinsic programme. $^{26}$ Nevertheless, a principal question emerging from previous as well as from more recent studies is whether control of necrosis resides within or outside cells.

By the present study we contribute to the lengthy dispute concerning necrosis as a passive versus a programmed biological event. We observed that fibroblasts, when cultured as clusters, express a distinct pattern of cellular decomposition. The cellular system employed here to analyse the processes of induction, commitment, and execution of necrosis is novel in the respect that cell death is triggered solely by the biological stimulus induced by three-dimensional arrangement of the culture. There evidently existed no involvement of any extrinsic toxic insult to cause artificial damage to the cells. The high level of tight cell-cell contacts present in these clusters led to downregulation of metabolic activity. This may imply contact inhibition, a process well documented in normal cells grown as monolayers. ${ }^{36}$ In our experiments, however, even though marginal elevation of $\mathrm{LDH}$ release and plasminogen activation was detectable in monolayers after 3 days in culture, no induction of COX-2 was evident. Even when the fibroblast monolayers were cultured at very high densities so as to better mimic spheroids, they showed no induction of COX-2 expression.
Here we provide, apparently for the first time, evidence at the molecular level that direct cell-cell contact in fibroblasts cultured as spheroids could initiate autologous regulatory signals, which ultimately trigger necrosis. Commitment to necrosis was an early event occurring during the first $3 \mathrm{~h}$ of initial cell clustering. Beyond this point of no return, the process was no longer reversible. Similar reversibility of cell death before $2-2.5 \mathrm{~h}$ was found in an in vivo study on ischaemic cell death and subsequent necrosis which employed peritoneally implanted fragments of liver in rats. ${ }^{37}$

We identified upregulation of COX-2 expression, a process associated with inflammation, as the most distinct molecular mechanism triggered by the dying fibroblasts. Activity of COX-2 leads to the production of prostanoids, key modulators of the inflammatory cascade. In the literature, the prevailing view has been that the inflammation accompanying necrosis is stimulated by cellular debris released during the process. ${ }^{26} \mathrm{We}$ provide experimental evidence that production of proinflammatory signalling molecules is selectively activated and is programmed in dying cells of a particular system undergoing necrosis. Induction of COX-2 expression was reversible and could be silenced when the causative factor, that is, forced homotypic cell-cell interaction in the present experimental arrangement, was eliminated, but only before the process reached the point of no return. We also found that activity of the caspase protease family is important for the induction of COX-2, possibly acting at the initiation phase of the death programme.

Prostanoids are secreted and exert their actions either in the cell that made them or in the neighbouring cells, in autocrine or in paracrine fashion, respectively. ${ }^{38}$ In our model of necrosis, increased COX-2 activity was accompanied by greatly enhanced production of the $\mathrm{PGs} \mathrm{PGI}_{2}, \mathrm{PGE}_{2}$, and $\mathrm{PGF}_{2 \alpha}$, indicating that COX-2 expression in clusters of fibroblasts can be enhanced and the clustering inhibited by $P G$ s associated with COX-2 activity, $\mathrm{PGl}_{2}$ being the most potent. When increased production of PGs abated, decrease in decomposition was evident. Taken together, this suggests an important autocrine role during necrosis for these PGs. Paracrine effects of prostanoids may lead to vasodilatation and increased permeability of postcapillary venules, early events in the inflammatory response. Specifically, $\mathrm{PGE}_{2}$, in an autocrine manner, may function as a mitogen in the initial cell population that is evidently becoming quiescent, or it may alter the ability of the cells to attach to a growth substrate and thus may enhance their propensity to survive, as indicated by some studies on PGE2. ${ }^{39}$ These properties of $\mathrm{PGE}_{2}$ may be relevant also for necrotizing cells. On the other hand, $\mathrm{PGI}_{2}$, the only prostanoid that is not a substrate for a specific transporter, has been shown to be an important antiaggregatory agent for platelets. ${ }^{15}$ This effect can be logically adopted also for the autocrine role of $\mathrm{PGI}_{2}$ in clustering fibroblasts as a protective feedback mechanism. In this context, one can speculate that decomposed cells with disrupted cell membranes may provide a means to liberate a particular PG from the cell where it is produced - to be targeted at neighbouring cells.

Based on a large body of experimental data, PGs act predominantly as proinflammatory mediators, but depending on the context, anti-inflammatory effects have been noted for some PGs. ${ }^{13}$ Specifically, such anti-inflammatory properties were linked to $P G D_{2},{ }^{40}$ which was in our system the least 
upregulated among PGs linked to increased expression of cOX-2.

The cellular and molecular basis of the necrosis caused in vivo by bacterial stimuli has been interpreted differently. ${ }^{41}$ Development of necrotic lesions in nude and knockout mice suggests that the whole process is dependent on the involvement of IFN- $\gamma$, IL-6, IL-12, and CD40 in the development of necrotic lesions. In those studies, no role for $\mathrm{NO}$ and the antiapoptotic molecule Bcl-2 was included. ${ }^{41,42}$ Our study, as well, showed no indication of upregulation of iNOS (results not shown) or of Bcl-2. Decomposition of our spheroids was accompanied by production of proinflammatory cytokines, for example, IL-6 and IL-8, but none or only marginal levels of anti-inflammatory cytokines (IL-4, IL-10, IL-13, or TNF- $\alpha$ ) (Kankuri et al., manuscript in preparation). Importantly, some studies on human tumour biopsies have indicated that cells surrounding necrotic areas of cancer lesions predominantly express IL-8. ${ }^{43,44}$

Our second important finding was that plasmin, a protease with wide substrate specificity, participated in the execution of the necrotic cellular mass. This protease is generated in the process of plasminogen activation, which represents a powerful and abundant extracellular proteolytic mechanism. Specifically, the proteolytic mechanism itself is able to form an amplification loop. We have previously demonstrated that plasmin generated at the cell surface by specific proteolytic cleavage can activate proactivators, which are components of the plasminogen activation cascade, for example pro-uPA, and can also create more binding sites for plasminogen in the extracellular matrix. ${ }^{45}$ Another consequence of increased proteolysis of membrane proteins by plasmin is the creation of new terminal lysine residues, which can serve as additional plasminogen-binding sites. ${ }^{33}$ Our results demonstrated that $\alpha$ enolase represented a regulatory component enhancing plasminogen activation in decomposing spheroids. This is in accordance with existing data on involvement of the enzyme in the upregulation of plasminogen activation on the surface of damaged cells. ${ }^{9}$ There is good reason to propose that intracellular proteolytic machinery is also active, along with the extracellular plasminogen activation, since the plasmin inhibitor aprotinin did not halt decomposition, a finding based on LDH activity (data not shown). Thus, the execution part of the necrosis is gradually enhanced by a self-driven proteolytic mechanism. It is important to note that, among the main components participating in regulation of the plasminogen activation cascade, only PAl-2 was upregulated. This was also evidenced on mRNA level by Northern blot analysis (data not shown). Interestingly, PAI-2 has in several studies been linked to the process of inflammation. ${ }^{46}$

Several lines of evidence suggest that PGs contribute to neovascularization by stimulation of enhanced production of proangiogenic growth factors. ${ }^{38}$ The most prominent among these is vascular endothelial growth factor (VEGF), which is also produced by cultured fibroblasts. ${ }^{47}$ Low levels of VEGF were also detected in the spheroids, although no upregulation was evident (data not shown). In addition, production and secretion of matrix metalloproteinases (MMPs), specifically MMP-2 and -9, during angiogenesis has been linked to COX-2 activity and PG production. ${ }^{48}$ MMP-2 activity was detected in early spheroid cultures but then diminished. Only marginal
MMP-9 activity was present throughout spheroid cultivation (data not shown). These results suggest that the process of necrosis in fibroblast spheroids does not signal for neoangiogenesis.

In conclusion, our results indicate that, rather than apoptosis, multicellular spheroids of dermal fibroblasts actually undergo necrotic cell death. Based on the results presented here, we conclude that the previous theory that necrosis is a solely passive catabolic process is incorrect. Certain recent results also suggest that necrosis, induced at least under in vitro conditions by extrinsic stimuli, has features of a programmed phenomenon. ${ }^{49}$ To clarify the overall programmed molecular machinery regulating this autostimulatory type of necrosis, as based on requirements for gene expression, transcriptome analysis by high-density microarrays is necessary. The model system presented here is likely to contribute to more precise identification of gene expression patterns involved in induction and execution of necrosis, and in this way elucidate the role of this mode of cell death in different pathologies. In addition, this cellular system may potentially be useful in assessment of the capacity of various therapeutic biomolecules to modulate necrosis.

\section{Materials and Methods}

\section{Materials}

Antibodies used in immunoblotting were: goat anti-actin antibody (Ab) (sc1615), mouse anti-Bax monoclonal $A b$ (MAb) (sc-7480), mouse anti-Bcl-2 MAb (sc-509), goat anti-calreticulin Ab (sc-6467), goat anti-Cox-1 Ab (sc1752), goat anti-Cox-2 Ab (sc-1746), rabbit anti-enolase Ab (sc-15343), and goat anti-Daxx Ab (sc-7000) from Santa Cruz Biotechnology (Santa Cruz, CA, USA); and mouse anti-Hsp70 MAb (SPA-810) and mouse antiHsp27 MAb (SPA-800) from Stressgen Biotechnologies (Victoria, BC, Canada). Mouse anti-Fas MAb (F22120) was from Transduction Laboratories (Lexington, KY, USA) and mouse anti-human p53 MAb (M7001) from DAKO (Glostrup, Denmark). The rabbit anti-COX-2 Ab (PG 27b) used in immunohistochemistry was from Oxford Biomedical Research (Oxford, MI, USA). The rabbit anti-tPA Ab (\#385R), rabbit anti-uPA Ab (\#389), goat anti-uPAR Ab (\#399G), mouse anti-PAl-1 MAb (\#380), mouse anti-PAl-2 MAb (\#3750) were from American Diagnostica (Greenwich, CT, USA). The secondary anti-mouse (S3721), anti-rabbit (S3731), and anti-goat (V115) alkaline phosphatase-conjugate Abs were from Promega (Madison, WI, USA).

The PGs PGE 2 (P5640), PGD (P6657), and PGF $_{2 \alpha}$ (P7652) were from Sigma (St. Louis, MO, USA), and the $P \mathrm{Pl}_{2}$ analog $\left(6 \alpha-P G l_{1}, \# 18110\right)$ and pinane thromboxane $A_{2}\left(T_{x A}\right)$ (\#19020) from Cayman Chemical (Ann Arbor, MI, USA). Indomethacin (17378) was from Sigma and the NS-398 (\#70590) from Cayman Chemical. The cell-permeable caspase inhibitor ZVAD-FMK was from Calbiochem (San Diego, CA, USA).

The $\alpha$-enolase mimetic peptide (amino-acid sequence ${ }^{257}$ DLDFKSPDDPSRYISP ${ }^{272}$ ) corresponding to the surface-exposed epitope of the enzyme ${ }^{34}$ and related scrambled peptide (amino-acid sequence SPDSYLPDRFDKSIDP) were synthesized at the Peptide Core Facility of the Haartman Institute.

\section{Cell cultures}

Human dermal fibroblasts (HFSF\#132) established from neonatal foreskin ${ }^{50}$ were kindly provided by Dr. Magdalena Eisinger, Memorial 
Sloan-Kettering Cancer Center, New York, NY, USA. These cells were cultured in DMEM/F-12 (1:1) medium (Gibco, Paisley, Scotland) supplemented with $10 \%$ fetal bovine serum (Gibco), $100 \mu \mathrm{g} / \mathrm{ml}$ streptomycin, and $100 \mathrm{U} / \mathrm{ml}$ penicillin and were used at passages $5-15$. All the experiments were performed with cells cultured in the medium containing $1.0 \mathrm{mM} \mathrm{Ca}^{2+}$, unless a different concentration is indicated. For the set of experiments on the calcium dependence of necrosis, $\mathrm{CaCl}_{2}$ was added to a low-calcium medium to reach the desired concentrations.

\section{Initiation and growth of spheroids}

U-bottom 96-well plates (Costar, Cambridge, MA, USA) were treated with $0.8 \%$ LE agarose (BioWhittaker, Rockland, ME, USA) prepared in sterile water to form a thin film of a nonadhesive surface. Fibroblasts were detached from culture dishes by trypsin/EDTA, and a single cellsuspension $\left(4 \times 10^{4}\right.$ cells $\left./ \mathrm{ml}\right)$ was prepared in a complete culture medium. To initiate spheroid formation, $250 \mu$ l aliquots were seeded into individual wells and the dishes incubated at $+37^{\circ} \mathrm{C}$ in $5 \% \mathrm{CO}_{2}$ atmosphere.

\section{Electron microscopy}

Multicellular clusters were collected at $12 \mathrm{~h}$ time intervals, and fixed by immersion in $0.5 \%$ glutaraldehyde and $0.1 \mathrm{M}$ phosphate buffer at $\mathrm{pH} 7.2$ for $2 \mathrm{~h}$ at $+4{ }^{\circ} \mathrm{C}$. The specimens were washed in $0.1 \mathrm{M}$ phosphate buffer at $\mathrm{pH} 7.2$ and then postfixed by $1 \% \mathrm{OsO}_{4}, 0.1 \mathrm{M}$ sucrose and $0.1 \mathrm{M}$ phosphate buffer at $\mathrm{pH} 7.2$ for $1 \mathrm{~h}$ at $+4^{\circ} \mathrm{C}$. After fixation, the specimens were dehydrated in a graded series of ethanol, washed in propylene oxide, and embedded in Epon 812 (Serva, Heidelberg, Germany). Thin sections were cut with a Reichert OmU3 ultramicrotome (Reichert Jung, Vienna, Austria) and poststained with uranyl acetate and lead citrate. Electron micrographs were taken with a transmission electron microscope JEOL 1200EX (JEOL, Tokyo, Japan) operated at $60 \mathrm{kV}$.

\section{Immunoblotting}

The cell samples were lysed directly in SDS-PAGE sample loading buffer (62.5 mM Tris- $\mathrm{HCl}, \mathrm{pH} 6.8,2 \%$ SDS, $20 \%$ glycerol, $5 \% \beta$-mercaptoethanol, and $0.005 \%$ bromphenol blue) supplemented with Complete miniprotease inhibitor mixture tablets (Roche, Mannheim, Germany) and boiled for $5 \mathrm{~min}$. Lysates were centrifuged at $14000 \mathrm{rpm}$ for $15 \mathrm{~min}$ to sediment particulate insoluble material. The samples were separated in SDS-PAGE (gradient of polyacrylamide $5-15 \%, 3.5 \%$ stacking gel). The proteins were transferred electrophoretically from the gel to a nitrocellulose membrane (Schleicher \& Schuell, Dassel, Germany), and transfer efficiency was verified by Ponceau-S staining. After blocking of the membrane with $2.5 \%$ low-fat dry milk in Tris-buffered saline $(20 \mathrm{mM}$ Tris$\mathrm{HCl}, 150 \mathrm{mM} \mathrm{NaCl}$, and $0.1 \%$ Tween 20, pH 7.5), it was incubated with specific primary antibodies, followed by an alkaline phosphataseconjugated secondary antibody (Promega). Protein bands were visualized according to the manufacturer's recommendations. Band densities were quantified by densitometry and expressed relative to the corresponding reference band densities.

\section{Measurement of caspase-3 activity}

The activity of caspase-3 was assayed using the EnzChek Caspase-3 assay Kit I (Molecular Probes, Eugene, OR, USA) according to the manufacturer's instructions. Briefly, cells were seeded and spheroids cultured as described above. Monolayers and spheroids were collected at 0,24 , and $48 \mathrm{~h}$ and then washed once with phosphate-buffered saline.
Cells $\left(1.2 \times 10^{5}\right)$ were lysed using $50 \mu$ l of lysis buffer and then incubated for $20 \mathrm{~h}$ with a caspase-3 substrate, Z-DEVD-AMC, which upon cleavage by caspase- 3 generates fluorescent products. Reactions were carried out at room temperature, and fluorescence was measured in a fluorescent plate reader using an excitation wavelength of $355 \mathrm{~nm}$ and an emission wavelength of $430 \mathrm{~nm}$. Monolayers stimulated with camptothecin $(13 \mu \mathrm{M})$ (Sigma) for $12 \mathrm{~h}$ were used as positive controls.

\section{Measurement of cell viability}

Cell respiration, an indicator of cell viability, was assayed by the mitochondria-dependent reduction of 3-[4,5-dimethylthiazol-2-yl]-2,5-diphenyltetrazolium bromide (MTT) to formazan (Roche). Identical aliquots of fibroblasts were simultaneously cultured as standard two-dimensional cultures in 12-well plates and multicellular clusters in 96-well plates as described above. At selected time points, the cultures were incubated with the substrate $(0.2 \mathrm{mg} / \mathrm{ml})$ for $30 \mathrm{~min}$ at $+37^{\circ} \mathrm{C}$; then the medium was aspirated and cells lysed in Tris- $\mathrm{HCl}$ SDS buffer. The extent of MTT conversion to formazan was quantified by measurement of optical density at $550 \mathrm{~nm}$ with a wavelength correction of $650 \mathrm{~nm}$, using a microplate reader (Multiscan MCC/340, Labsystems, Helsinki, Finland).

\section{Assessment of spheroid decomposition and DNA damage}

Cell decomposition was measured by $\mathrm{LDH}$ released into culture medium employing a colorimetric assay (Roche). At indicated time points, conditioned culture media from the cultures were collected and spun down to remove residual cell debris, and $100 \mu \mathrm{l}$ was mixed with $100 \mu \mathrm{l}$ of $\mathrm{LDH}$ assay reagent. Spectrophotometric analysis was performed at room temperature with a microplate reader measuring optical density at $492 \mathrm{~nm}$ and correction at $620 \mathrm{~nm}$. Basal LDH activity levels measured in culture medium were subtracted from the values obtained prior to analysis.

TUNEL staining was performed with the In situ Cell Death Detection Kit (Fluorescein) from Roche, following the manufacturer's instructions.

Oligonucleosomal DNA fragmentation was assessed by the electrophoresis in $1.8 \%$ agarose of DNA extracted by DNAazol (Gibco) from spheroids collected at time intervals. DNA was visualized by staining with ethidium bromide $(1 \mu \mathrm{g} / \mathrm{ml})$.

\section{Immunohistochemistry}

Immunohistochemistry was performed with the Discovery Slide Stainer (Ventana Medical Systems, Tucson, AZ, USA). The spheroids were fixed in $4 \%$ paraformaldehyde/PBS before being embedded in paraffin. Sections $(5 \mu \mathrm{m})$ were deparaffinized twice in xylene and rehydrated in graded series of ethanol. The slides were equilibrated in alkaline phosphate formula K (APK, Ventana) before the immunohistochemistry procedure and then incubated with anti-COX-2 primary polyclonal antibody (Oxford Biomedical Research) at 1:200 dilution. The staining was performed with the Ventana red alkaline phosphatase Fast red detection kit.

\section{Estimation of prostanoid concentrations in conditioned media}

The cells were seeded and spheroids cultured as described above. The culture media, conditioned by $4 \times 10^{4}$ cells $/ \mathrm{ml}$, were collected at the indicated time points, cellular debris was spun down at $14000 \mathrm{rpm}$ for 
$15 \mathrm{~min}$ and the supernatant used to assay concentrations of individual PGs. Quantitation of $P \mathrm{PI}_{2}$ (as its metabolite 6-keto-PGF $\mathrm{F}_{1 \alpha}$ ), $P \mathrm{PE}_{2}, \mathrm{PGD}_{2}$ (after methoximation), and $\mathrm{TxA}_{2}$ (as its metabolite $\mathrm{TxB}_{2}$ ) in medium conditioned by spheroids or monolayer fibroblasts was carried out with corresponding specific prostanoid ELISA kits and reagents from Cayman Chemical. Concentrations of $\mathrm{PGF}_{2 \alpha}$ were quantitated with the ELISA kit and reagents from R\&D Systems (Minneapolis, MN, USA).

\section{Effects of exogenous prostanoids and COX inhibitors on spheroids}

The cells were seeded as above, and the prostanoids $(100 \mu \mathrm{g} / \mathrm{ml})$ were added. The spheroid volume during the clustering process was calculated from the diameter estimated by microscopy with the aid of an ocular grid. The spheroids were cultured for $36 \mathrm{~h}$, then collected and processed for immunoblotting analysis as described above. COX-2 and actin were detected by specific antibodies. Indomethacin was dissolved in absolute ethanol and NS-398 in DMSO; these inhibitors were added to cell cultures to achieve final concentrations of $0.0005-250 \mu \mathrm{M}$. Control cultures contained the vehicle at the highest concentration.

\section{Plasmin generation in spheroids}

The cells were cultured for at least two passages in culture medium supplemented with $10 \%$ plasminogen-depleted FCS, prepared by passing heat-inactivated FCS twice through a lysine-Sepharose column (Pharmacia, Uppsala, Sweden). Spheroid formation was initiated in the same culture medium as specified above, and at indicated time points, $50 \mu \mathrm{g} / \mathrm{ml}$ of human plasminogen (American Diagnostica) was added with or without respective competing peptides or antibodies. Plasmin generation by the spheroids was allowed to proceed for $2 \mathrm{~h}$, after which the clusters were washed twice with Dulbecco's balanced salt solution supplemented with $0.2 \%$ BSA, and cell-bound plasmin was eluted with $1 \mathrm{mM}$ tranexamic acid (both from Sigma). The eluted plasmin was assayed by its thioesterase activity by addition of $200 \mu \mathrm{l}$ of a solution containing $200 \mathrm{mM}$ potassium phosphate ( $\mathrm{pH} 7.5), 200 \mathrm{mM}$ potassium chloride, $0.1 \%$ Triton X-100, $220 \mu \mathrm{M}$ Z-lysine thiobenzyl ester (Peninsula Laboratories,

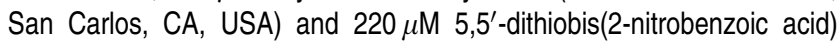
(Sigma). Absorbances were recorded in a microplate reader at $405 \mathrm{~nm}$.

\section{Statistical analysis}

For continuous variable data, means and standard errors of the mean were computed and, when appropriate, comparisons between two groups were made with ANOVA followed by the Bonferroni postcomparison test with statistical significance set at $P<0.05$. Statistical analyses, curvefitting algorithms, and $\mathrm{IC}_{50}$ calculations were performed using Graph Pad Prism 3.02 (GraphPad Software Inc., San Diego, CA, USA).

\section{Acknowledgements}

We are especially grateful to I Suomalainen for her help and expertise concerning immunohistochemistry and to $\mathrm{C}-\mathrm{H}$ von Bonsdorff for advice with electron microscopy. The expertise and help of $L$ Eurajoki on the ELISA measurements is gratefully appreciated. We thank $P$ Salmenperä for carrying out the caspase- 3 activity assays. Carolyn Norris author-edited the language. JB was supported during his sabbatical leave from the Cancer Research Institute by travel fellowships from the EMBO and Yamagiwa Yoshida of the UICC. The project was partially sponsored by
Sigrid Jusélius Foundation funding of AV. Correspondence and requests for material should be addressed to AV.

\section{References}

1. Baehrecke EH (2002) How death shapes life during development. Nat. Rev. Mol. Cell Biol. 3: 779-787

2. Kerr JF, Wyllie AH and Currie AR (1972) Apoptosis: a basic biological phenomenon with wide-ranging implications in tissue kinetics. Br. J. Cancer 26: 239-257

3. Majno G and Joris I (1995) Apoptosis, oncosis, and necrosis. An overview of cell death. Am. J. Pathol. 146: 3-15

4. Hengartner MO (2000) The biochemistry of apoptosis. Nature 407: 770-776

5. Rich T, Allen RL and Wyllie AH (2000) Defying death after DNA damage. Nature 407: 777-783

6. Shi $Y(2002)$ Mechanisms of caspase activation and inhibition during apoptosis. Mol. Cell 9: 459-470

7. Arends MJ and Wyllie AH (1991) Apoptosis: mechanisms and roles in pathology. Int. Rev. Exp. Pathol. 32: 223-254

8. Casiano CA, Ochs RL and Tan EM (1998) Distinct cleavage products of nuclear proteins in apoptosis and necrosis revealed by autoantibody probes. Cell Death Differ. 5: 183-190

9. O'Mullane MJ and Baker MS (1998) Loss of cell viability dramatically elevates cell surface plasminogen binding and activation. Exp. Cell Res. 242: 153-164

10. Kroemer G, Dallaporta B and Resche-Rigon M (1998) The mitochondrial death/ life regulator in apoptosis and necrosis. Annu. Rev. Physiol. 60: 619-642

11. Wyllie AH (1987) Apoptosis: cell death in tissue regulation. J. Pathol. 153: 313316

12. Brash AR (2001) Arachidonic acid as a bioactive molecule. J. Clin. Invest. 107: 1339-1345

13. Funk CD (2001) Prostaglandins and leukotrienes: advances in eicosanoid biology. Science 294: 1871-1875

14. Vane JR, Bakhle YS and Botting RM (1998) Cyclooxygenases 1 and 2. Annu. Rev. Pharmacol. Toxicol. 38: 97-120

15. Herschman HR (1996) Prostaglandin synthase 2. Biochim. Biophys. Acta 1299: $125-140$

16. Iyer VR, Eisen MB, Ross DT, Schuler G, Moore T, Lee JC, Trent JM, Staudt LM, Hudson Jr. J, Boguski MS, Lashkari D, Shalon D, Botstein D and Brown PO (1999) The transcriptional program in the response of human fibroblasts to serum. Science 283: 83-87

17. Columbano A (1995) Cell death: current difficulties in discriminating apoptosis from necrosis in the context of pathological processes in vivo. J. Cell. Biochem. 58: $181-190$

18. Bonfoco E, Krainc D, Ankarcrona M, Nicotera P and Lipton SA (1995) Apoptosis and necrosis: two distinct events induced, respectively, by mild and intense insults with $\mathrm{N}$-methyl-D-aspartate or nitric oxide/superoxide in cortical cell cultures. Proc. Natl. Acad. Sci. USA 92: 7162-7166

19. Sauter B, Albert ML, Francisco L, Larsson M, Somersan S and Bhardwaj N (2000) Consequences of cell death: exposure to necrotic tumor cells, but not primary tissue cells or apoptotic cells, induces the maturation of immunostimulatory dendritic cells. J. Exp. Med. 191: 423-433

20. Mueller-Klieser W (1997) Three-dimensional cell cultures: from molecular mechanisms to clinical applications. Am. J. Physiol. 273: C1109-C1123

21. Sutherland RM (1988) Cell and environment interactions in tumor microregions: the multicell spheroid model. Science 240: 177-184

22. Kandel J, Bossy-Wetzel E, Radvanyi F, Klagsbrun M, Folkman J and Hanahan D (1991) Neovascularization is associated with a switch to the export of bFGF in the multistep development of fibrosarcoma. Cell 66: 1095-1104

23. Carlsson J, Nilsson K, Westermark B, Ponten J, Sundstrom C, Larsson E, Bergh J, Pahlman S, Busch C and Collins VP (1983) Formation and growth of multicellular spheroids of human origin. Int. J. Cancer 31: 523-533

24. Zhang Y, Cao HJ, Graf B, Meekins H, Smith TJ and Phipps RP (1998) CD40 engagement up-regulates cyclooxygenase-2 expression and prostaglandin $E_{2}$ production in human lung fibroblasts. J. Immunol. 160: 1053-1057

25. Dimmeler S, Haendeler J, Nehls M and Zeiher AM (1997) Suppression of apoptosis by nitric oxide via inhibition of interleukin- $1 \beta$-converting enzyme 
(ICE)-like and cysteine protease protein (CPP)-32-like proteases. J. Exp. Med. 185: 601-607

26. Wyllie AH, Kerr JF and Currie AR (1980) Cell death: The significance of apoptosis. Int. Rev. Cytol. 68: 251-306

27. Wolvekamp MC, Darby IA and Fuller PJ (1998) Cautionary note on the use of end-labelling DNA fragments for detection of apoptosis. Pathology 30: 267-271

28. Ferri KF and Kroemer G (2001) Organelle-specific initiation of cell death pathways. Nat. Cell Biol. 3: E255-E263

29. Mosser DD, Caron AW, Bourget L, Denis-Larose C and Massie B (1997) Role of human heat shock protein hsp70 in protection against stress-induced apoptosis. Mol. Cell. Biol. 17: 5317-5327

30. Johnson S, Michalak M, Opas M and Eggleton P (2001) The ins and outs of calreticulin: from the ER to the extracellular space. Trends Cell Biol. 11: 122-129

31. Wong E, DeLuca C, Boily C, Charleson S, Cromlish W, Denis D, Kargman S, Kennedy BP, Ouellet M, Skorkey K, O'Neill GP, Vickers PJ and Riendeau D (1997) Characterization of autocrine inducible prostaglandin $\mathrm{H}$ synthase-2 (PGHS-2) in human osteosarcoma cells. Inflamm. Res. 46: $51-59$

32. Berridge MJ, Lipp P and Bootman MD (2000) The versatility and universality of calcium signalling. Nat. Rev. Mol. Cell Biol. 1: 11-21

33. Plow EF, Herren T, Redlitz A, Miles LA and Hoover-Plow JL (1995) The cell biology of the plasminogen system. FASEB J. 9: 939-945

34. Arza B, Felez J, Lopez-Alemany R, Miles LA and Munoz-Canoves P (1997) Identification of an epitope of $\alpha$-enolase (a candidate plasminogen receptor) by phage display. Thromb. Haemost. 78: 1097-1103

35. Hoyer-Hansen G, Ronne E, Solberg H, Behrendt N, Ploug M, Lund LR, Ellis V and Dano K (1992) Urokinase plasminogen activator cleaves its cell surface receptor releasing the ligand-binding domain. J. Biol. Chem. 267: 18224-18229

36. Harris AK (1999) A dozen questions about how tissue cells crawl. Biochem. Soc. Symp. 65 : 315-341

37. Majno G, La Gattuta M and Thompson TE (1960) Cellular death and necrosis: chemical, physical and morphological changes in rat liver. Virchows Arch. Pathol. Anat. 333: 421-465

38. Prescott SM and Fitzpatrick FA (2000) Cyclooxygenase-2 and carcinogenesis. Biochem. Biophys. Acta 1470: M69-M78
39. Wang MY and Liehr JG (1995) Lipid hydroperoxide-induced endogenous DNA adducts in hamsters: possible mechanism of lipid hydroperoxide-mediated carcinogenesis. Arch. Biochem. Biophys. 316: 38-46

40. Gilroy DW, Colville-Nash PR, Willis D, Chivers J, Paul-Clark MJ and Willoughby DA (1999) Inducible cyclooxygenase may have anti-inflammatory properties. Nat. Med. 5: 698-701

41. Florido M, Cooper AM and Appelberg R (2002) Immunological basis of the development of necrotic lesions following Mycobacterium avium infection. Immunology 106: 590-601

42. Ehlers S, Benini J, Held HD, Roeck C, Alber G and Uhlig S (2001) $\alpha \beta$ T cell receptor-positive cells and interferon- $\gamma$, but not inducible nitric oxide synthase are critical for granuloma necrosis in a mouse model of mycobacteria-induced pulmonary immunopathology. J. Exp. Med. 194: 1847-1859

43. Desbaillets I, Diserens AC, De Tribolet N, Hamou MF and Van Meir EG (1999) Regulation of interleukin-8 expression by reduced oxygen pressure in human gliobastoma. Oncogene 18: 1447-1456

44. Kunz M, Hartmann A, Flory E, Toksoy A, Koczan D, Thiesen HJ, Mukaida N, Neumann M, Rapp UR, Brocker EB and Gillitzer R (1999) Anoxia-induced upregulation of interleukin-8 in human malignant melanoma. A potential mechanism for high tumor aggressiveness. Am. J. Pathol. 155: 753-763

45. Stephens RW, Pollanen J, Tapiovaara H, Leung KC, Sim PS, Salonen EM, Ronne E, Behrendt N, Dano K and Vaheri A (1989) Activation of pro-urokinase and plasminogen on human sarcoma cells: a proteolytic system with surfacebound reactants. J. Cell Biol. 108: 1987-1995

46. Buechler $C$ (2001) Lipoprotein (a) up-regulates the expression of the plasminogen activator inhibitor 2 in human blood monocytes. Blood 97: 981-986

47. Trompezinski S, Pernet I, Schmitt D and Viac J (2001) UV radiation and prostaglandin E2 up-regulate vascular endothelial growth factor (VEGF) in cultured human fibroblasts. Inflamm. Res. 50: 422-427

48. Shattuck-Brandt RL, Lamps LW, Heppner Goss KJ, DuBois RN and Matrisian LM (1999) Differential expression of matrilysin and cyclooxygenase-2 in intestinal and colorectal neoplasms. Mol. Carcinogen. 24: 177-187

49. Kitanaka $C$ and Kuchino $Y$ (1999) Caspase-independent programmed cell death with necrotic morphology. Cell Death. Differ. 6: 508-515

50. Eisinger M, Flick RB, Bizik J and Arita Y (1991) Epidermal cell derived factor (EDF): partial purification and characterization. Prog. Clin. Biol. Res. 365: 375-389 